\title{
LA RISA EN EL PUERPERIO
}

\section{Laughter in the puerperium}

\author{
María del Carmen Curioso Chávez*
}

\section{Resumen}

El presente artículo, intenta mostrar características emocionales por las que atraviesan las mujeres puérperas, entre ellas la que se destaca en el presente artículo: La Risa. Luego de alrededor de cuarenta semanas de gestación y la expectativa de una nueva etapa de vida, junto a un nuevo ser, podremos observar en el puerperio emociones extremas que van desde la risa hasta el llanto.

Palabras clave: Risa, Puerperio, depresión, humor.

\begin{abstract}
The present article tries to show emotional characteristics being experienced by postpartum women, including that stands out in this article: Laughter. After about forty weeks of gestation and the expectation of a new stage of life. with a new being, we can observe in the postpartum extreme emotions ranging from laughter to tears.
\end{abstract}

Key words: Laughter, puerperium, depression, mood.

* Psicologa. Especialista en Competencias Clave. Dirección de Formación Profesional y Capacitación Laboral. Ministerio de Trabajo. maria.curioso@hotmail.com 
Como madre moderna, cuando decidí que quería tener hijos, leí todo sobre el bebé, y me preparé mental y físicamente para el gran momento. Estaba segura de que eso me facilitaría mucho la labor. Sin embargo, un buen día, me encontré aún en pijama a las dos de la tarde, sin haberme duchado en dos días, dolorida y cansada del postparto y dando el pecho a mi bebé mientras mi hermana me visitaba. Miré a mi hermana, que no tiene hijos, y al verla sentada junto a mí vestida, maquillada y delgada, de pronto me puse a llorar y dije: "No sé si puedo hacer esto". Me refería, claro está, a ser madre.

-"Creo que ya es demasiado tarde," me respondió ella.

Las dos nos miramos y al momento rompimos a reír. En momentos abrumadores, la risa es la mejor terapia...

...Mi hermana agarró en brazos a la niña y yo me duché, me arreglé y salimos las tres a dar un paseo. (Ladish, 2011)

Es común que las mujeres nos preparemos para uno de los eventos más importantes en nuestra vida: La llegada de nuestro propio bebé. Cuando somos pequeñas, solemos jugar con muñecas, transformándolas en mamás de bebés imaginarios. Una vez ya adultas, durante la dulce espera, leemos cuanta revista de bebés esté a nuestro alcance, todo esto con el objetivo de prepararnos para el momento más esperado: dar a luz a un nuevo ser. El sueño de una mujer se hace realidad al tenerlo en brazos, de quién se espera, complementará alegremente la familia en todas sus dinámicas y dimensiones.

El texto de referencia sin embargo, muestra una pequeña dosis de emociones adversas por las que una madre puérpera atraviesa, definiendo el puerperio como el periodo de vida de la mujer que sigue al parto que dura entre seis a ocho semanas (Peralta, 2010). Luego de la dulce espera, comienzan a tomar forma, algunos estados emocionales como la tristeza, el enojo y la depresión. Una de las razones por las que surgen estas emociones, suele ser el tiempo insuficiente con el que se cuenta para el correcto cuidado del bebé y el de la misma madre, además de la poca tolerancia con la que ésta pudiera contar. Desde el baño, la elección de la ropa del día, el cambio constante de pañales, el tiempo de lactancia (se suma a esto la preocupación de brindar o no lactancia exclusiva), la visita de páginas de internet en temas referidos al cuidado del lactante (alimentación, abrigo, vacunas, sueño, etc.), los cuidados del sueño del bebé y las pocas horas de descanso de los padres, hacen de ésta una etapa única en la vida de una mujer, pudiendo transformar la alegría inicial en cuadros depresivos en esta importante etapa: El puerperio.

¿Cómo poder contrarrestar este estado?, es la pregunta a la que muchas puérperas buscan respuesta. Para esto, se hace necesario, entre otras cosas, contar $\mathrm{y}$ poner en práctica un bagaje de pensamientos y emociones con las cuales la mayoría de las personas contamos, entre ellas la alegría, la felicidad ó la expresión física de ambas: La risa. Recordemos que la felicidad, la alegría, la actitud positiva, la risa, la sonrisa y la carcajada son elementos propios de nosotros mismos (Guía, 2010).

En esta ocasión, haremos un pequeño análisis de la importancia de la risa como técnica de afrontamiento de pensamientos y emociones negativas por las cuales una persona pudiera atravesar.

Hace aproximadamente once años atrás, una de mis primas se encontraba gestando. Me impresionaba la dedicación y el cuidado que tenía para con su bebé, aún estando éste dentro del vientre. Su horario de comida y la calidad de la misma, el descanso y la preocupación de cómo llevar un mejor embarazo, hacían notar que el futuro sobrino tendría una madre totalmente dedicada y amorosa. La sorpresa fue grande cuando luego de unos días de nacido, los llantos del neonato incrementaban la intolerancia de su madre y ponían a prueba su paciencia y dedicación.

Casos como éstos no son únicos, suceden a muchas mujeres y más aún a aquellas cuyas características de ansiedad, irritabilidad (para consigo misma y con los demás) se muestran presentes. Es probable que la fatiga y el insomnio, pueden ocasionar actitudes como el rechazo al propio bebé (no querer cogerlo, ni tocarlo, ni verlo, tal como si él o ella fuera el motivo por el que se siente infeliz) o rechazo hacia la pareja (la intolerancia hacia éste se hace frecuente, además de 
culparlo de forma consciente o inconsciente del cambio en el nuevo estilo de vida ante la llegada del bebé). Ya no es extraño ver o escuchar a través de los medios de comunicación, madres que atentan contra su vida y la de sus pequeños debido al estado depresivo por el que están atravesando. Si bien el presente artículo hace mención de éstas escenas, no justifica dicha acción.

\section{LA DEPRESIÓN POSTPARTO}

Durante el embarazo, las mujeres reciben mil y un consejos sobre cómo enfrentar las náuseas matutinas, cómo calmar el dolor de pechos o qué hacer para evitar los dolores de espalda y la retención de líquidos. Pero existen también quienes no reciben mucha información y quienes no tienen acceso a las mismas. Las mujeres primerizas por ejemplo suelen tener muchas inquietudes sobre el bebé que estará por venir; su frustración se activa cuando reciben múltiple información al respecto y todas ellas diferentes, no sabiendo finalmente por cuál de ellas optar y cuál de ellas dejar.

Hay ciertos factores que hacen propensas a unas mujeres más que a otras, de presentar cuadros depresivos post-parto - debe considerase como postparto todo el período que la madre necesita para recuperar la condición endocrina y nutricional que tenía antes de embarazarse y toda la etapa de transición en que el niño o niña es tan dependiente de la madre. Este período es variable y puede durar algunos meses y aún más de un año si la lactancia es prolongada (Díaz, 2006) -. Dichos factores pueden ser considerados como genéticos, químicos, hormonales, psicológicos, sociales o por estrés (Montero, 2007). Sin embargo, mucho influyen las situaciones y el entorno por el que se esté atravesando. En el caso que tenga que dejar su carrera, su trabajo o estudios, o que éstos tengan un orden prioritario en sus vidas más que la consolidación de ser madre; un hijo puede producir ansiedad en la puérpera, dejando brotar la ira por el nuevo ser y el nuevo estilo de vida.

Es necesario, en primera instancia no forzar a la madre, ya que eso podría ocasionar que acabe por aborrecer a su bebé. En estos casos se recomienda la observación constante hacia la madre, el apoyo emocional de la familia y también de los amigos, además de momentos y actividades de distracción. Con el paso del tiempo la madre volverá a ser la misma y es probable que mantenga una mejor disposición ante el cuidado y crianza del bebé. Debemos considerar la importancia de contar con un adecuado grupo de referencia; si tomamos en cuenta que existen madres adolescentes, madres con pareja no consolidada, hijos no deseados, pérdida de familiares en el tiempo pronto al puerperio, pocos amigos debido a no haber sabido estrechar lazos de amistad adecuados, podríamos deducir que este tiempo de puerperio será poco menos llevadero.

La revista Archives of General Psychiatry, a través de su artículo "Psychiatric Disorders in Pregnant and Postpartum Women in the United States" (Vesga y cols. 2008), demuestra que la probabilidad de presentar cuadros depresivos en el periodo de post parto, aumenta en mujeres que tuvieron episodios anteriores de depresión, falta de apoyo familiar, baja autoestima o un embarazo estresante; lo que nos ayuda a inferir que las características depresivas no suceden en todas las mujeres. Por su lado, el Dr.Rozados - Miembro de PSICOMAG y la "Foundation in Special Consultative Status with the Economic and Social Council of the United Nations" -, afirma que "la depresión postparto puede afectar tanto, a mujeres que están felizmente casadas como a aquellas que están en permanente conflicto con sus parejas".

En la casuística, algunas madres mencionan haberse sentido tristes durante los primeros días del puerperio. Muchas mujeres (en especial primerizas), refieren sentirse frustradas al ver que sus bebés sólo comen y duermen (cosa normal y común en los recién nacidos), haciendo notar la importancia de que cada gestante deba contar con una preparación pre-natal adecuada y completa; una preparación emocional, física y psicológica, para esta nueva etapa que está por enfrentar.

Tal y como lo expresan en el portal de Geosalud, la depresión postparto es una de las enfermedades más frecuentes tras el parto, que afecta a una de cada diez puérperas.

Los síntomas más frecuentes son: 
1. Tristeza, síntoma más frecuente de la depresión postparto, donde las pacientes se sienten bajas de ánimo, infelices y desgraciadas la mayor parte del tiempo, pudiendo empeorar en algún momento particular del día, como por las mañanas o por las tardes.

2. Irritabilidad, volcada de forma usual en el recién nacido, la familia o el esposo. Va acompañada muchas veces de la sensación de tristeza.

3. Fatiga. La madre con depresión postparto se siente tan agotada que llega a pensar que padece alguna enfermedad física.

4. Insomnio. Cuando por fin la madre se va a la cama puede que tenga dificultad para conciliar el sueño, o si duerme, puede que se despierte muy pronto.

5. Pérdida de apetito o aumento excesivo del mismo; generalmente no tienen ni tiempo ni ganas de comer. Algunas madres deprimidas comen en exceso para aliviar su malestar psicológico y luego se sienten culpables y molestas con su gordura.

6. Incapacidad para disfrutar, lo que antes era interesante o placentero, ahora no lo es. Esto involucra las relaciones sexuales. Las madres en este tiempo están más interesadas en la lactancia del bebé y en todo lo que involucra a él que el sexo pasa a segundo o tercer plano. Esto se agudiza en el caso de las puérperas con depresión.

7. Desbordamiento. Las madres con depresión postparto tienen la sensación de no disponer de tiempo para nada, ni para ellas mismas. Piensan que nada hacen. Algunas pueden llegar a sentirse un objeto expendedor de leche.

8. Ansiedad. Suele ser aguda y se puede presentar en forma de temor a quedarse sola con el bebé por miedo a que éste grite, no quiera comer, se ahogue, se caiga o se haga daño de cualquier otra forma. Algunas madres deprimidas perciben a su bebé como un objeto. Es frecuente que la paciente desee ser constantemente tranquilizada por su pareja, su familia, su médico o cualquier otra persona.

Imagino a las puérperas cesareadas, quienes tienen que atender al recién nacido, pese a la operación a la que recientemente se han visto expuestas. Definitivamente, ante este acontecimiento hago mención a Planchart (Guía 2010) que menciona que la alegría es una valiosa herramienta para ayudar a recuperar a los pacientes, cuyas vidas deben dirigirse hacia la felicidad.

La depresión postparto hace de la maternidad una mala experiencia y dificulta la relación entre la pareja. De forma que lo mejor es detectar lo antes posible este trastorno para tratarlo precozmente, intentando dirigir a la persona hacia la búsqueda y encuentro de la felicidad.

\section{¿Qué hacer frente a una depresión postparto?}

La práctica profesional en centros de salud de la zona alto andina, me han permitido observar que algunos profesionales que asisten a la puérpera en esta etapa, pasan por alto estos síntomas o le dan un valor menor considerándola como un simple maternity blues (Gonzales, 2006) o depresión de tipo transitoria. El decirle a la madre que lo que está pasando es consecuencia de un cuadro de depresión postparto (diagnóstico de la depresión) puede ser de gran ayuda, ya que por lo menos sabrá a qué tiene que enfrentar.

El siguiente paso es involucrar a la pareja de la paciente de forma que pueda comprender qué es lo que a ella le está sucediendo. Hay que considerar que él también puede haber estado sufriendo las consecuencias de esta depresión. La familia también juega un rol importante de apoyo emocional en esta etapa, sin descartar lo sustancial de las relaciones amicales.

El tercer paso es recibir apoyo profesional con un tratamiento diseñado especialmente para la madre puérpera. Para esto es necesario recordar a la madre durante el tratamiento que:

- No es necesario ser una súper madre.

- Hacer amistad con otras parejas que estén pasando por la misma etapa, facilita este proceso.

- Aprovechar las oportunidades de descanso; las pequeñas siestas son buenas. Una siesta corta alarga la vida (Pérez, 2011)

- Alimentarse adecuadamente.

- Encontrar tiempo para disfrutar con su pareja. 
- Intentar intimar con la pareja. Un beso, un abrazo, una caricia, o un mimo puede ser bastante reconfortable.

- No ser muy crítica. El cansancio y la irritabilidad de ambos puede conducir a discusiones frecuentes que sólo debilitarían la relación.

- Pedir ayuda cuando se necesite.

La perseverancia en esta etapa suele ser una cualidad importante para mantener una actitud positiva. Ésta sumada a la famosa alquimia mental o transformación de pensamientos - término acuñado por Ralph M. Lewis, alrededor de los años 50 - es seguro que llevarán a la puérpera a la transformación de pensamientos y actitudes negativas hacia pensamientos $\mathrm{y}$ actitudes positivas.

\section{NUESTRA RISA}

"Una sonrisa no cuesta nada y produce mucho.

Enriquece a quienes la reciben, sin empobrecer a quien la da.

No dura más que un instante, pero su recuerdo a veces es eterno.

Nadie es demasiado rico para prescindir de ella.

Nadie es demasiado pobre para no merecerla.

Da felicidad en el hogar y apoyo en el trabajo.

Es el símbolo de la amistad.

Una sonrisa da reposo al cansado.

Anima a los más deprimidos.

No se puede comprar, ni prestar, ni robar, pues son cosas que no tienen valor, hasta el momento en que se da.

Y si alguna vez se tropieza con alguien

que no sabe dar una sonrisa más,

sea generoso, dele la suya.

Porque nadie tiene tanta necesidad de una sonrisa Como el que no puede dársela a los demás.

(Mahatma Gandhi)

Aristóteles sostenía que un bebé no es persona hasta que ríe. Aunque la frase suene un poco dura, no podemos negar que se perfila a ser cierta ante la experiencia de algunas puérperas. Ver reír a un bebé hace florecer los sentimientos más sublimes de una madre. Las personas al verlo percatamos lo sencillo que puede ser expresar nuestras emociones.
Cuando un bebé ríe, su risa suele ser contagiosa y enternecedora. Cuando el niño se da cuenta que a los adultos les gusta su risa, la repite constantemente. Aunque el niño nazca ciego y sordo igual ríe (Moreno, 2004). Según este autor, los niños están mucho más dispuestos a reírse que los adultos, un pequeño hasta los seis años de vida se ríe un promedio de 300 veces al día, mientras que un adulto lo hace menos de la tercera parte. Esto nos lleva a reflexionar porqué atendemos al bebé cuando llora y no lo atendemos cuando está riendo. Le enseñamos que cuando tiene hambre tiene que llorar, en lugar de reír. Cuando está sucio y hay que cambiarle de pañales también tiene que llorar para cambiarlo, cuando debiéramos enseñarle a reír por el lindo regalo de darnos a nosotros los adultos parte de su ser que son, creámoslo o no, su orina o sus excrementos.

Carlos Guía (2010), menciona que la risa provoca la liberación de las endorfinas conocidas como las hormonas de la felicidad, además de aportar múltiples beneficios físicos y psicológicos. Un artículo referido por él sobre el diario La Jornada de México, señala:

- Con cada carcajada se ponen en marcha cerca de 400 músculos, incluidos 15 de la cara y algunos del tórax, abdomen y estómago, que sólo se pueden ejercitar a través de la risa.

- La columna vertebral y la cervical se estiran, usualmente son dos regiones corporales donde se acumulan las tensiones. Se estimula el bazo y se eliminan las toxinas. También evita el estreñimiento y mejora la eliminación de la bilis.

- Los lagrimales lubrican y limpian los ojos. La carcajada hace vibrar la cabeza y se despejan la nariz y el oído. Contribuye a limpiar las paredes arteriales de pequeños cúmulos de colesterol.

- Los pulmones mueven 12 litros de aire, a diferencia de los 6 habituales, lo que mejora la respiración y aumenta la oxigenación de los tejidos.

- La risa, libera dopamina que posee efectos calmantes. Por eso se utiliza para terapias de convalecencia que requieren una movilización rápida del sistema inmunológico.

- Previene el infarto, fortaleciendo los pulmones y el corazón. 
- Elimina el insomnio.

- Disminuye el estrés.

- Alivia la depresión.

- Conduce al proceso de regresión y de afrontamiento.

- Mejora la autoestima.

- La risa exterioriza emociones y sentimientos.

Guía (2010), menciona que Freud, en sus ensayos, atribuyó a la carcajada el poder de liberar al organismo de energía negativa. Sostiene también que la risa es la mejor vacuna contra la soberbia, la opresión y la intolerancia.

¿Hace cuánto tiempo que tu risa no contagia a otros a tu alrededor? Si la respuesta hace alusión a un tiempo corto deberás sentirte satisfecha, pero si tiende a extenderse, es necesario que te tomes un espacio para evaluar tus emociones, tus actitudes personales y las relaciones para con tu entorno.

Erasmo de Rotterdam, por los años 1500, refería que reírse de todo es de tontos, pero no reírse de nada es de estúpidos. Si es capaz de reírse de sus problemas se produce un cambio significativo en su visión del mundo. Por ello, reír constituye lo más inteligente que podemos hacer (Guía, 2010)

"La risa es el instrumento más valioso con el que cuenta la humanidad para desarrollar y mantener activo el niño que todos llevamos dentro, ése al que por miedo o vergüenza, no dejamos salir de nuestro interior" (Pérez, 2010). Si aprendemos a usarla incrementaremos tanto nuestra satisfacción personal como nuestra productividad. (Guía, 2010)

El mismo autor refiere que los efectos de la risa son mejores cuando dura por lo menos un minuto. Las endorfinas, a las que se llama también Hormonas de la Felicidad, se producen aun cuando la risa fuera forzada y son capaces de reemplazar la sensación de dolor por la euforia. La risa funciona cambiando los sentimientos negativos en positivos. Recordemos que la risa aunque sea fingida, el cuerpo la considerará como que es de verdad y es contagiosa al igual que el bostezo.
La 'American Association for Therapeutic Humor', en su página web, tiene un aviso que dice: "Atención, el humor puede ser peligroso para su enfermedad"; cualquiera sea el caso, es mejor estar enfermo de risa que de llanto. Con esto no queremos negar la importancia que tiene el llanto como técnica de expresión de sentimientos y emociones, éstas en la práctica terminan siendo saludables. Pérez (2011), nos dice que llorar es bueno y tanto la risa como el llanto ayudan a la prevención de enfermedades y cuidado del cuerpo.

\section{Del Humor a la Risa}

El buen humor nos da la sensación de sentirnos a gusto con nosotros mismos.

En consejería psicológica, algunas parejas reconocen que el humor juega un papel muy importante dentro del matrimonio, ya que el humor en una relación, suele restar seriedad a los enojos cotidianos.

Si hablamos de la fisiología cerebral del humor, Moreno (2004) nos da a conocer que la parte del cerebro que genera el humor es la que corresponde al Área Motora Suplementaria, en el Lóbulo Pre frontal, donde residen la creatividad, la visión de futuro, la espiritualidad y la diferenciación entre el bien y el mal. En otras palabras lo más sofisticado del cerebro del hombre. Ante esta aseveración, se puede inferir que el humor termina siendo una técnica importante para contrarrestar los estados estresantes y depresivos del puerperio.

Es necesario diferenciar los términos humor y risa, recordando que la risa es sólo un reflejo. La una no incluye necesariamente la otra.

\section{De Cosquillas a Carcajadas}

Guía (2010), rescata al aporte que genera la carcajada a la vitalidad y la energía humana-en su libro nos recuerda que veinte minutos de carcajadas, supone el mismo ejercicio para el corazón que 3 minutos de remo -. Atribuye que la carcajada se produce frente a un estímulo humorístico de gran intensidad, y sirve de elemento socializador. 
Las cosquillas le dan al ser humano la cualidad de socializar. Los bebés sienten gran satisfacción de que se les hagan, es una vía de conexión con sus padres y familiares. Es claro que éstas deben ser reguladas, ya que un bebé no podría, al igual que un adulto, recibir grandes dosis de cosquillas sin generar desbordamiento y estrés. Si hacemos un alto a nuestras actividades y recordamos a quienes hicimos cosquillas, percataremos que sólo hemos realizado esta acción con personas cercanas a nosotros o con aquellas a quienes les tenemos un afecto especial.

Tanto las cosquillas como la carcajada terminan siendo elementos socializantes. Es increíble pensar que existan personas que nunca recibieron una cosquilla o que jamás experimentaron la sensación de emitir una excitante carcajada.

\section{LA ACTITUD POSITIVA}

Cuidar permanente de un bebé, además de no descuidar las labores personales, familiares y profesionales, se convierte no sólo es una labor titánica, sino que nos transforma en la muy recordada "mujer maravilla" que debe y puede hacerlo todo. La diferencia radica en que no tenemos poderes sobrenaturales que nos permitan realizar todas estas actividades, ni somos seres omnipresentes para suplir cada una de ellas; sin embargo, de alguna u otra manera muchas de éstas terminan siendo hechas.

Una actitud positiva es aquella disposición mental que tenemos las personas frente a una situación determinada, la cual nos ayuda a resolver problemas que suelen aparecer en el camino (Guía, 2010). Benjamín Franklin nos menciona: Vivid siempre en un ambiente de optimismo.

$\mathrm{Al}$ escuchar de actitud positiva, muchas mujeres pueden realizarse la siguiente pregunta: ¿cómo puede una puérpera ser positiva en sus actitudes o mantener una buena disposición mental frente al ajetreo diario del bebé, el esposo y sus quehaceres personales, familiares y profesionales? La respuesta a esta pregunta la encontrará cada una de acuerdo a su dinámica familiar, a su visión personal del mundo y cómo lo desafía, utilizando sus recursos personales, haciendo uso de su capacidad de resiliencia y sus niveles de afrontamiento a cada situación. Tal como nos menciona Guía (2010), la risa y una actitud positiva son valiosas herramientas que contribuyen al mejoramiento y desarrollo de la creatividad, las relaciones interpersonales, la comunicación, el aprendizaje la productividad y al fortalecimiento de nuestro sistema inmunológico.

Mantener una actitud positiva frente a la vida usualmente despeja nuestras mentes para tomar decisiones más acertadas, además nos ayuda a resolver problemas cotidianos con mayor facilidad. Una actitud positiva nos lleva a buscar soluciones a los problemas que con la contraparte, el negativismo, no llegaríamos a ver. Si bien es cierto, el comportamiento de una mujer puede variar de un modo radical con volubilidad pasmosa (Pérez, 2011), más aún en la etapa del puerperio, es importante durante la psicoterapia llegar a un reconocimiento personal de estos cambios, además de afianzar la poca o mucha actitud positiva que la puérpera pudiera presentar para la obtención de mejores resultados. Como menciona Minchinton (2006), mejor piensa en mejorar las cosas mejorando tu autoestima. Sé tú misma, sé sincera.

\section{REFERENCIAS}

AATH (2013) Association for applied and therapeutic humor. Recuperado de http://www.aath.org/

Diaz, S. (2006). El periodo postparto. Documentos UNICEF. Recuperado de http://www.unicef.cl/ lactancia/docs/mod04/POST-PARTO.pdf

Geosalud (2013) Depresión postparto. Recuperado de http://geosalud.com/depresion/depresion_ postparto.htm

Gonzales, A. (2006). Estados emocionales en el postparto. Medicina Naturalista. Recuperado de http://dialnet.unirioja.es/descarga/articulo/ 1985554.pdf

Guía, C. (2010). Detrás de la Risa. El arte y la ciencia del bienestar (4a ed.). Venezuela: Neuroguía 23.

Ladish, L. (2011). Evitar la tristeza post parto. Guía de About.com. Recuperado de http://mamalatina. about.com/b/2011/07/01/tristeza-post-parto.htm 
Minchinton, J. (2006). 50 maneras de hacer que su amor dure para siempre. ( $1^{\mathrm{a}}$ ed.) Barcelona: Sirio.

Montero, I. (2007). Programa de Formación de Formadores/as en Perspectiva de Género en Salud. Universidad de Valencia. Recuperado de http:// www.msc.es/organizacion/sns/planCalidadSNS/ pdf/equidad/06modulo_05.pdf

Moreno, L. (2004). Ríase no sea enfermo. ( $1^{\text {a }}$ ed.) Ecuador: Jumandi.

Peralta, O. (2010). Aspectos Clínicos del Puerperio. Manual para el entrenamiento del personal de los servicios de salud. Recuperado de http:// www.icmer.org/documentos/lactancia/puerperio_ octavio.pdf

Pérez, J. (2011). Viva sano día a día. Claves para sentirse bien de salud. ( $1^{\mathrm{a}}$ ed.) Perú: Planeta.
Puntriano Rosas César (2012) Implementación e Importaciones de Lactarios Maternos en las Empresas. Recuperado de http://www. esan.edu.pe/conexion/actualidad/2012/09/17/ implementacion-lactarios-maternos-empresas/ ?utm_source $=$ Conexi\%B3n+ESAN\&utmcanpain $=6634031558-$ Conexi $\%$ C3\%B3nESAN Semanal\&utm-medium=email

Rozados Ricardo (2013) Depresión post parto Recuperado de http://www.depresion.psicomag. com/post_parto.php

Vesga, O., Blanco, C., Keyes, K., Olfson, M., Grant, B. y Hasin, D. (2008). Psychiatric Disorders in Pregnant and Postpartum Women in the United States. Arch Gen Psychiatry, 65(7), 805-815. doi: 10.1001/archpsyc.65.7.805

Fecha de recepción: 26 de octubre de 2012

Fecha de aceptación: 6 de mayo de 2013 